\title{
Effects of emotion on item and source memory in young and older adults
}

\author{
PATRICK S. R. DAVIDSON, CRAIG P. MCFARLAND, and ELIZABETH L. GLISKY \\ University of Arizona, Tucson, Arizona
}

\begin{abstract}
Emotional experiences are easier to remember than neutral ones, but whether memory for all aspects of an experience is improved by emotion remains unclear. Some researchers have argued that the influence of emotion on memory is different for item than for source information, whereas others have argued that emotion affects both similarly. Also, whether item and source memory are affected by emotion in older people in the same way as in young people is currently unclear. We examined item and source memory for emotional and neutral materials in young and older adults. Memory for emotional items was superior to memory for neutral items, whereas there was no difference in source memory. Overall, item and source memory were poorer in older people than in young people, but emotion seemed to have a similar effect on both age groups. Although emotional content was remembered better than neutral content, this benefit did not apply to source memory. However, varying the emotionality of the source (i.e., the voice in Experiment 3) improved memory for the source, and this effect was greater in young than in older people. Tone of voice had no effect on item memory in older people, but the effect was variable in the young and may depend on the extent to which the tone of voice moderates the interpretation of the content.
\end{abstract}

Although the relation between emotion and memory is complex, emotional life experiences are often remembered more vividly and more robustly than everyday events (for reviews, see Neisser \& Libby, 2000; Pillemer, 1998). Similarly, in controlled laboratory experiments, memory is usually better for emotionally arousing items than for neutral ones, regardless of valence (i.e., how positive or negative the stimulus is), familiarity, the nature of the materials (e.g., verbal vs. nonverbal; Bradley, Greenwald, Petry, \& Lang, 1992; Doerksen \& Shimamura, 2001; Hamann, Monarch, \& Goldstein, 2000; Kensinger \& Corkin, 2003; LaBar \& Phelps, 1998; cf. Talmi \& Moscovitch, 2004), and many other characteristics. There are many interrelated explanations for this finding: Emotional items may be more distinctive than neutral ones, organized more easily into categories, rehearsed more often, and/or forgotten at a lower rate (for reviews, see Christianson, 1992; Reisberg \& Heuer, 2003).

Recently, there has been renewed interest in whether the beneficial effects of emotion extend to all aspects of

This article represents a portion of the dissertation completed by P.S.R.D. in partial fulfillment of the requirements for a doctoral degree at the University of Arizona. Funding was provided by fellowships from the Natural Sciences and Engineering Research Council of Canada and the Canadian Institutes of Health Research to P.S.R.D. and by a grant from the National Institute on Aging (A.G. 14792) to E.L.G. We thank Andrea Soule, Jesse Winer, and Nicole Heyden for screening the older adults and for compiling and checking experimental data; Jasmeet Pannu, Connie Clarke, and Jonathan Forster for suggestions on using DMDX; and Cyma Van Petten, Al Kaszniak, Lee Ryan, and Steve Rapcsak for helpful comments on this project. Correspondence may be addressed to P. S. R. Davidson, Department of Psychology, University of Alberta, Edmonton, AB, T6G 2E9 Canada (e-mail: psd@ualberta.ca). an episodic memory. For example, researchers have distinguished between memory for the focal or core content of an episode and memory for its context. This distinction can be described as one between memory for items (i.e., content, such as pictures or words) and memory for source (i.e., the spatial, temporal, perceptual, or affective context in which that content was experienced, such as the location where the picture was seen or the voice that said the word). In general, source memory tasks are more difficult than item memory tasks, may require additional processes, and are affected by different variables than are item memory tasks, so it seems reasonable to think that emotion could have different effects on the two. Two main hypotheses have been advanced by cognitive psychologists about how emotion might affect memory for contextual, or source, information. On the one hand, Easterbrook (1959) has argued that in emotional situations, people narrow their attention to the information that they think is central, focal, or salient (i.e., what is usually considered the item) and ignore peripheral or background information (i.e., what is usually considered the source). On the other hand, the tick rate hypothesis (Revelle \& Loftus, 1992; see also Kahneman, 1973) asserts that under conditions of emotional arousal, people pay greater attention to all aspects of an event, both central and peripheral, by sampling or encoding the environment at a greater rate or in greater detail. Although both theories agree that emotional arousal benefits item memory, they make different predictions about the effects of emotion on source memory. Whereas the Easterbrook prediction suggests that source memory should be worse under conditions of emotional arousal than is normal, the tick rate hypothesis suggests that it should instead be better. 
The fate of source or contextual information in emotional memory has been examined in only a few studies, and the findings have been mixed. In most, participants have studied pictures, some that have featured emotional stimuli or situations in the foreground (e.g., a car accident or a surgical operation) and others that have been neutral. Although some studies have supported the Easterbrook (1959) claim by showing that memory for background information is poorer for emotional pictures than for neutral ones (e.g., Burke, Heuer, \& Reisberg, 1992; Christianson \& Loftus, 1987, 1991; Heuer \& Reisberg, 1992; Kensinger, Piguet, Krendl, \& Corkin, 2005), others have, instead, supported the tick rate hypothesis (Kahneman, 1973; Revelle \& Loftus, 1992) by showing that background information is remembered better in emotional pictures than in neutral ones (e.g., Heuer \& Reisberg, 1990; Libkuman, Nichols-Whitehead, Griffith, \& Thomas, 1999; see also Wessel, van der Kooy, \& Merckelbach, 2000, for inconsistent results within the same set of experiments). One possible reason for the mixed findings is that in these paradigms, it is often difficult to define and distinguish central from peripheral features.

More direct studies of item and source memory using emotion in the laboratory have been rare, but there is evidence that the benefits of emotion on item memory may extend to source memory, at least under some circumstances. For example, Doerksen and Shimamura (2001) showed young people words printed in one of two colors of ink (Experiment 1) or against one of two colored backgrounds (Experiment 2). Half of the words were emotional (e.g., glory, slaughter), and half were neutral (e.g., cotton, route). In both experiments, after a brief delay, source memory (i.e., memory for the ink color or background of a word) was significantly better for the emotional words than for the neutral ones (see also D'Argembeau \& Van der Linden, 2004; Dutton \& Carroll, 2001; Kensinger \& Corkin, 2003; MacKay \& Ahmetzanov, 2005). On the other hand, Shimamura (2003) recently reported a failure to replicate the previously mentioned enhancement of source memory by emotion, and Read and Craik (1995) found, in a study of voice recognition, that using an emotional, as opposed to a neutral, sentence did not improve participants' subsequent recognition of the speaker.

Given the paucity of direct evidence and the contradictory evidence across different paradigms, it remains unclear whether the Easterbrook (1959) or the tick rate (Revelle \& Loftus, 1992; Kahneman, 1973) hypothesis offers a better description of the relation between emotion and source memory. Furthermore, this relation may not be the same in older adults as in young people.

\section{Aging and Item and Source Memory}

Item and source memory are differentially sensitive to aging. Item memory is less likely to decline with age than is source memory (Brown, Jones, \& Davis, 1995; Ferguson, Hashtroudi, \& Johnson, 1992; Henkel, Johnson, \& De Leonardis, 1998; McIntyre \& Craik, 1987; Schacter, Kaszniak, Kihlstrom, \& Valdiserri, 1991; Spencer \& Raz, 1994; Trott, Friedman, Ritter, \& Fabiani, 1997; for reviews, see Prull, Gabrieli, \& Bunge, 2000; Spencer \&
Raz, 1995). As well, the two are differentially related to the function of two regions of the brain in aging: Whereas item memory appears to be more related to medial temporal lobe processes, source memory appears to be more dependent on frontal lobe processes (e.g., Glisky, Polster, \& Routhieaux, 1995; but see Henkel et al., 1998).

Aging and emotional arousal. Aging has little impact on skin conductance and subjective reactions to emotional experiences (David, Littrell, Kaszniak, \& Nielsen, 2002; Levenson, Carstensen, Friesen, \& Ekman, 1991; Levine \& Bluck, 1997; Malatesta \& Kalnok, 1984), and despite poorer item memory overall, older adults show a benefit of emotion on item memory that is similar to, if not greater than, that for young people (Carstensen \& TurkCharles, 1994; Charles, Mather, \& Carstensen, 2003; Denberg, Buchanan, Tranel, \& Adolphs, 2003; Kensinger, Brierley, Medford, Growdon, \& Corkin, 2002; Kensinger et al., 2005; Leigland, Schulz, \& Janowsky, 2004; Yoder \& Elias, 1987).

The picture with respect to source memory, however, is less clear. On the one hand, our recent studies of flashbulb memory (FM), which require people to recollect where, when, or from whom they learned about an emotional event in the real world (e.g., the September 11th, 2001, terrorist attacks; Brown \& Kulik, 1977) have shown no differences between young and older adults (Davidson, Cook, \& Glisky, 2006; Davidson \& Glisky, 2002; see also Otani et al., 2005; Wright, Gaskell, \& O'Muircheartaigh, 1998; but see Cohen, Conway, \& Maylor, 1994, and Tekcan \& Peynircioğlu, 2002, for conflicting findings). We speculated that the emotional arousal associated with FMs may have enhanced the processes important for the encoding of source information, eliminating the age-related deficit usually found in laboratory studies of source memory. If this is the case, then if emotional materials were used in a laboratory paradigm, the usual negative effects of aging on source memory might be absent or significantly less than those for neutral stimuli.

On the other hand, in one of the few previous laboratory studies to examine emotion, source memory, and aging (Hashtroudi, Johnson, Vnek, \& Ferguson, 1994), older adults showed impairments, relative to young adults. Young and older adults read or listened to lines from a play. They were asked to focus on how they felt when thinking about the lines (the affective condition) or on the content of what was said (the factual condition). Memory for who read the lines was worse in the affective than in the factual focus condition, and older adults were impaired only in the affective condition. The authors argued that an affective or internal focus at encoding impairs source memory by taking attention away from the source or from the connection between the item and the source. Older adults may be more likely than young adults to have an internal focus (i.e., on their own feelings; Johnson, Nolde, \& De Leonardis, 1996) in these situations.

Consistent with this finding is research suggesting that older adults sometimes have difficulty integrating different aspects of an experience in memory (e.g., Mitchell, Johnson, Raye, Mather, \& D'Esposito, 2000) and may, 
therefore, focus only on one. Naveh-Benjamin and Craik (1996) presented words (i.e., items) spoken by one of two voices (i.e., sources) to young and older people, and later tested item and source memory. People paid attention either to the item (by judging the pleasantness of each word) or to the source (by rating the pitch in which each word was spoken). In young people, the former condition led to better memory for both item and source than did the latter condition. In older adults, however, focusing on the item led to better item memory but worse source memory than did the latter condition. These results are consistent with the idea that although young people can often integrate item and source information, older people are less capable of doing so and, thereby, can exhibit a trade-off between these different aspects of memory. Thus, in older people, focus on the item may improve memory for the item at the expense of memory for the source (see Jurica \& Shimamura, 1999, for a possible example of an itemsource trade-off in memory, using the generation effect; but see Geghman \& Multhaup, 2004). To the extent that emotional items attract attention, source information may be poorly remembered.

In summary, some naturalistic studies have suggested that older adults are more likely to encode source information in cases of emotion, whereas a laboratory study suggested that older adults are less likely to encode source information in situations involving emotion. It is not obvious how to reconcile these contradictory findings. The emotional arousal level is almost certainly greater in naturalistic settings than in the laboratory, and other variables might differ between the two. Nevertheless, there are few laboratory studies concerning the effects of emotion on source memory in either young or older adults. The present article reports a systematic investigation of the effects of emotion on item and source memory in young and older adults.

\section{EXPERIMENT 1}

This study was designed to test, in a laboratory setting, the effects of emotion on memory for words and for the voices speaking the words, using a paradigm similar to that described in Glisky et al. (1995; Glisky, Rubin, \& Davidson, 2001). Some previous studies with young adults have shown benefits of emotion on both item and source memory (e.g., Doerksen \& Shimamura, 2001; Kensinger $\&$ Corkin, 2003). Given these findings, we predicted that both item and source memory would be better for emotional than for neutral materials in young people. Previous research has also shown that item memory in older adults benefits from emotion to at least the same degree as in the young (Charles et al., 2003; Denberg et al., 2003; Kensinger et al., 2005; Leigland et al., 2004; Yoder \& Elias, 1987), if not more so (Carstensen \& Turk-Charles, 1994). Therefore, in the present experiment, we expected that in older adults, as in young adults, item memory would be better for the emotional than for the neutral materials.

The outcome of the source memory test in older adults was less easily predicted. On the one hand, our FM studies
(Davidson et al., 2006; Davidson \& Glisky; 2002) suggest that in older adults, source memory might be better for emotional than for neutral materials (as in young people). Specifically, older adults may be impaired in source memory for neutral materials but may be unimpaired for emotional ones. The emotional nature of the materials may enhance processes associated with attention to, or linking of, source and item information and may eliminate the source memory deficit seen with neutral materials. On the other hand, the results of Hashtroudi et al. (1994) and Naveh-Benjamin and Craik (1996) suggest that in older adults, source memory may be poorer for emotional than for neutral items. Consistent with the Easterbrook (1959) hypothesis, the attention-attracting emotional items may interfere with the processing of source information. If this is the case, older adults, who tend to have difficulty spontaneously linking item and source information at encoding (Glisky et al., 2001), may show increased source memory deficits for the emotional stimuli.

\section{Method}

Participants. Thirty-two young adults (age, $M=21.61$ years, $S D=5.16$; education, $M=13.67$ years, $S D=1.06$ ) were recruited from undergraduate psychology classes at the University of Arizona. Testing was discontinued with 3 additional young people (because of failure to understand the source memory test instructions, because of a computer malfunction, or because English was the participant's second language and he did not know the meaning of several studied words).

Thirty-two older adults were recruited (age, $M=75.31$ years, $S D=6.28$; education, $M=16.03$ years, $S D=2.29$ ) from our laboratory pool and were paid $\$ 6 / \mathrm{h}$ to participate. All were community dwelling, with normal or corrected-to-normal vision and hearing, and none reported drug or alcohol abuse or neurological or psychiatric illness (including depression and dementia). Four extra older participants were excluded (because of failure to understand instructions, report of possible neurological damage, or computer malfunction).

Materials. Forty-eight words were selected from the set of Affective Norms for English Words (ANEW; Bradley \& Lang, 1999), a large set of words previously rated by college undergraduates for valence (from $1=$ unpleasant to $9=$ pleasant), arousal (from $1=$ calm to $9=$ excited), and dominance (from $1=$ controlled to $9=$ in control). Half of the words were chosen to be emotional (i.e., those that obtained the highest ratings of arousal, regardless of valence or other factors; e.g., cash, rollercoaster, and rape), and the other half were neutral (i.e., those that obtained the lowest ratings of arousal, regardless of valence or other factors; e.g., cozy, foot, and dustpan). Words that contained the same root as (e.g., sex and sexy) or were synonyms of (e.g., dagger and knife) previously selected words were excluded from the list. Each of the emotional and the neutral word sets was further divided into two lists, yielding four lists of 12 words each. An independent 2 (word type: emotional or neutral) $\times 2$ (list: 1 or 2) ANOVA showed that the two emotional word lists consisted of words with significantly higher arousal ratings $(M \mathrm{~s}=7.11$ and 7.52$)$ than did the two neutral word lists $(M \mathrm{~s}=3.17$ and 3.20$)[F(1,44)=$ $1,167.30, p<.001]$. Because the emotional words were more likely to be negative than positive, a similar ANOVA examining valence showed that the two emotional lists contained words that were marginally more negative $(M \mathrm{~s}=4.18$ and 4.10$)$ than those in the two neutral word lists $(M \mathrm{~s}=5.33$ and 5.66) $[F(1,44)=3.91, p<.06]$. All four lists were similar in dominance $(M \mathrm{~s}=5.00$ and 4.62 for emotional and 4.75 and 4.96 for neutral), word length in syllables $(M \mathrm{~s}=1.58$ and 2.08 for emotional and 1.83 and 1.83 for neutral), word frequency $(M \mathrm{~s}=31.58$ and 24.33 for emotional and 13.67 and 
Table 1

Proportions of Items Rated As "Emotional" by Young and Older Adults in Experiment 1

\begin{tabular}{llllll}
\hline & \multicolumn{2}{c}{ Young Adults } & & \multicolumn{2}{c}{ Older Adults } \\
\cline { 2 - 3 } \cline { 5 - 6 } \multicolumn{1}{c}{ Stimuli } & $M$ & $S D$ & & $M$ & $S D$ \\
\hline Item Memory & & & & \\
$\quad$ Neutral items & .22 & .16 & & .24 & .15 \\
$\quad$ Emotional items & .75 & .18 & & .84 & .13 \\
Source Memory & & & & \\
$\quad$ Neutral items & .19 & .13 & .31 & .16 \\
Emotional items & .70 & .19 & .78 & .15 \\
\hline
\end{tabular}

24.08 for neutral; Kučera \& Francis, 1967), and abstractness $(M \mathrm{~s}=$ 3.54 and 3.80 for emotional and 3.20 and 3.18 for neutral, where $1=$ concrete and $9=$ abstract $)(F \mathrm{~s}<1.31)$. Words were recorded by a male voice and a female voice, using Goldwave software (2002) on a personal computer.

Procedure. The participants gave informed consent when taking part in these experiments, which were approved by the university's human participants protection committee. Stimuli were presented auditorily through loudspeakers in two separate study-test blocks: one for source memory and the other for item memory (items were counterbalanced between the item and the source tasks). Previous pilot testing indicated that the order of these blocks had little effect on performance (Glisky et al., 2001), so in all cases, source memory was examined first.

In the source memory study phase, the participants listened to words from one emotional and one neutral list, randomly mixed; half of each list was spoken by the male voice, and the other half by the female voice, in random order. In addition, two words were presented at the beginning and two at the end of the study list to absorb primacy and recency effects. People were asked to indicate whether each word was emotional or neutral by pressing the appropriate key on the computer keypad after they had heard it. The study list was repeated twice more with the same instructions, with the words presented in a different random order each time. ${ }^{1}$ No mention was made of a subsequent memory test. The source memory test phase followed immediately and consisted of a two-alternative forced choice (2-AFC) recognition test for the voice that spoke each of the studied words; each word was re-presented as at study in the original voice that had spoken it (the target), paired with the same word spoken by the opposite-sex voice (the distractor). In half the trials, the target was presented before the distractor, and in the other half, the order was reversed. The participants were asked to press the appropriate key to indicate whether the first or the second voice had spoken the word originally. After a brief ( $\sim 1 \mathrm{~min})$ interval, the item memory block followed.

The item memory study phase used the two other word lists, one emotional and one neutral, and was identical to that of the source memory study phase, with the exception that the words were presented only once. Again, no mention was made of a subsequent memory test, which followed immediately. The participants were requested to recall, using pencil and paper, all the words presented in the item study phase.

\section{Results}

The mean proportion of stimuli rated as emotional by each age group is shown in Table 1. For both the item and the source memory study phases, separate 2 (age group: young or older) $\times 2$ (word type: emotional or neutral) mixed ANOVAs were conducted, with similar results. Older adults were more likely than the young adults to rate words as emotional $\left[F(1,62)=3.30, M S_{\mathrm{e}}=0.03\right.$, $p=.07$, and $F=9.92, M S_{\mathrm{e}}=0.03, p=.003$, for item and source memory, respectively; $\alpha$ was set at .05 for this and all the subsequent analyses], and not surprisingly, the emotional words were more likely than the neutral words to be rated as "emotional" by the participants $[F(1,62)=$ $565.47, M S_{\mathrm{e}}=0.02, p<.001$, and $F=354.01, M S_{\mathrm{e}}=$ $0.02, p<.001$, for item and source memory, respectively]. In neither case was the interaction between age and word type significant $(F \mathrm{~s}<2.35)$. Because the participants' subjective ratings of emotionality showed somewhat poor correspondence with the normative ratings, particularly in the young people (i.e., only $73 \%$ of the emotional words were rated as such), all the analyses were reconducted using subjective ratings of emotionality.

Recall on the item memory test is shown in the left half of Table 2. A 2 (age group: young or older) $\times 2$ (word type: emotional or neutral) mixed ANOVA based on the normative ratings showed that the young people recalled significantly more words than did the older adults $[F(1,62)=12.33$, $\left.M S_{\mathrm{e}}=0.02, p=.001\right]$. Overall, the emotional words were significantly more likely to be recalled than were the neutral words $\left[F(1,62)=86.91, M S_{\mathrm{e}}=0.01, p<.001\right]$. The interaction was not significant $(F<1)$. Analyses based on the subjective ratings produced a similar pattern of effects.

In source memory, however, the pattern was different, as can be seen in the right half of Table 2 . When normative ratings were used, the young people had reliably better source recognition than did the older adults $[F(1,62)=$ $\left.30.61, M S_{\mathrm{e}}=0.03, p<.001\right]$; there was a main effect of word type $\left[F(1,62)=4.17, M S_{\mathrm{e}}=0.01, p=.05\right]$, and the interaction was significant $\left[F(1,62)=4.84, M S_{\mathrm{e}}=0.01\right.$, $p=.03]$ : In the young people, source memory was better when the words were emotional than when they were neutral $[t(31)=3.40, p=.002]$. The older adults showed no such advantage, with source memory scores equivalent for the emotional and the neutral words $(t<1)$. When the analyses were based on the participants' own ratings of emotionality, however, there was still an overall age difference in source memory $\left[F(1,62)=30.20, M S_{\mathrm{e}}=\right.$ $0.03, p<.001]$ but no effect of the emotional content of

Table 2

Item and Source Memory Ratings in Young and Older Adults in Experiment 1

\begin{tabular}{|c|c|c|c|c|c|c|c|c|}
\hline \multirow[b]{3}{*}{ Ratings } & \multicolumn{4}{|c|}{$\begin{array}{l}\text { Item Memory } \\
\text { (Recall) }\end{array}$} & \multicolumn{4}{|c|}{$\begin{array}{c}\text { Source Memory } \\
(2-A F C)\end{array}$} \\
\hline & \multicolumn{2}{|c|}{$\begin{array}{l}\text { Young } \\
\text { Adults }\end{array}$} & \multicolumn{2}{|c|}{$\begin{array}{l}\text { Older } \\
\text { Adults }\end{array}$} & \multicolumn{2}{|c|}{$\begin{array}{l}\text { Young } \\
\text { Adults }\end{array}$} & \multicolumn{2}{|c|}{$\begin{array}{l}\text { Older } \\
\text { Adults }\end{array}$} \\
\hline & $M$ & $S D$ & $M$ & $S D$ & $M$ & $S D$ & $M$ & $S D$ \\
\hline Normative & & & & & & & & \\
\hline $\begin{array}{c}\text { Neutral } \\
\text { items }\end{array}$ & .15 & .13 & .08 & .09 & .70 & .15 & .56 & .15 \\
\hline $\begin{array}{l}\text { Emotional } \\
\text { items }\end{array}$ & .32 & .11 & .22 & .13 & .78 & .14 & .56 & .15 \\
\hline $\begin{array}{r}\text { Subjective } \\
\text { Neutral } \\
\text { items }\end{array}$ & .17 & .14 & .08 & .11 & .73 & .13 & .55 & .18 \\
\hline $\begin{array}{l}\text { Emotional } \\
\text { items }\end{array}$ & .30 & .12 & .22 & .12 & .75 & .16 & .57 & .13 \\
\hline
\end{tabular}

Note-2-AFC, two-alternative forced choice. 
the words and no interaction with age $(F \mathrm{~s}<1)$, indicating that source memory was equivalent for emotional and neutral words in both the young and the older adults. Source memory performance in the older adults, although close to the floor, was significantly above chance $\left[t_{\mathrm{s}}(31)=2.27\right.$ and 2.36 for the emotional and the neutral stimuli, respectively; $p \mathrm{~s}=.03$ ].

Pearson correlations were computed to assess the extent to which performance on the item memory and source memory tests was related. In neither age group were item and source memory correlated for either the emotional or the neutral items $(r \mathrm{~s}<|.07|)$.

\section{Discussion}

Consistent with the existing literature, item memory was positively influenced by emotion: Recall of the emotional words was reliably greater than recall of the neutral words. The benefit conferred by emotion on item memory was about the same in the young and the older groups (similar to that in Denberg et al., 2003; Yoder \& Elias, 1987), although overall levels of recall were lower in the older adults.

An initial examination of the source memory results, based on the normative ratings of emotionality, suggested that the patterns might be different in young and older adults, with the young adults showing a benefit of emotion on source memory and the older adults failing to show any benefit. The participants' emotional ratings, however, indicated that the young people rated $25 \%-30 \%$ of the emotional words as neutral, whereas the ratings of the older people were more in line with the normative ratings. Reanalysis of the data on the basis of subjective judgments indicated no effect of emotionality of the words on source memory in either age group. Because two other published studies had shown beneficial effects of emotion on source memory in young people (i.e., Doerksen \& Shimamura, 2001; Kensinger \& Corkin, 2003), we decided to try to replicate our finding in young people, using a paradigm similar to the one used in those studies.

In Experiment 2, we presented young adults with emotional and neutral words visually in one of two colors (the sources), as Doerksen and Shimamura (2001) and Kensinger and Corkin (2003) had done. In two versions of the experiment, we varied the incidental/intentional nature of the study and the form of the retrieval task.

\section{EXPERIMENT 2A}

\section{Method}

Participants. Thirty-two young adults (age, $M=18.53$ years, $S D=0.84$; education, $M=12.53$ years, $S D=0.84$ ) were recruited from undergraduate psychology classes at the University of Arizona. Data from 2 additional participants who failed to follow instructions were discarded.

Materials and Procedure. The materials and procedure were identical to those in Experiment 1, except that words were presented visually for $3 \mathrm{sec}$ on a computer screen, with a 2-sec interstimulus interval, in either purple or orange (instead of being presented auditorily in either a male or a female voice). For both the item and the source tasks, the participants rated each word as emotional or neutral. Study lists were presented three times, and people were not informed of the subsequent memory tests. The source recognition test was 2-AFC, with the participants seeing a studied word in both colors and picking the color in which it had been shown originally by making a keypress. The item test was free recall.

\section{Results}

Figures $1 \mathrm{~A}$ and $1 \mathrm{~B}$ show proportional scores from the item and source memory tests. A pair of planned withinsubjects $t$ tests was conducted, comparing memory for the neutral items with memory for the emotional items. On the item memory test, the emotional words $(M=$ .31) were significantly more likely to be recalled than the neutral words $(M=.17)[t(31)=4.59, p<.001]$. However, source memory was unaffected by whether the words were emotional $(M=.65)$ or neutral $(M=.66$; chance $=.50)(t<1)$. As in the previous experiments, there was no significant correlation between item and source memory performance for either the emotional $(r=.08)$ or the neutral $(r=.15)$ stimuli. Also, as in the last experiment, the participants' subjective ratings of emotionality did not correspond exactly with the normative ratings, so all the analyses were also conducted on the basis of the subjective ratings. This did not, however, change the pattern of results for either item or source memory.
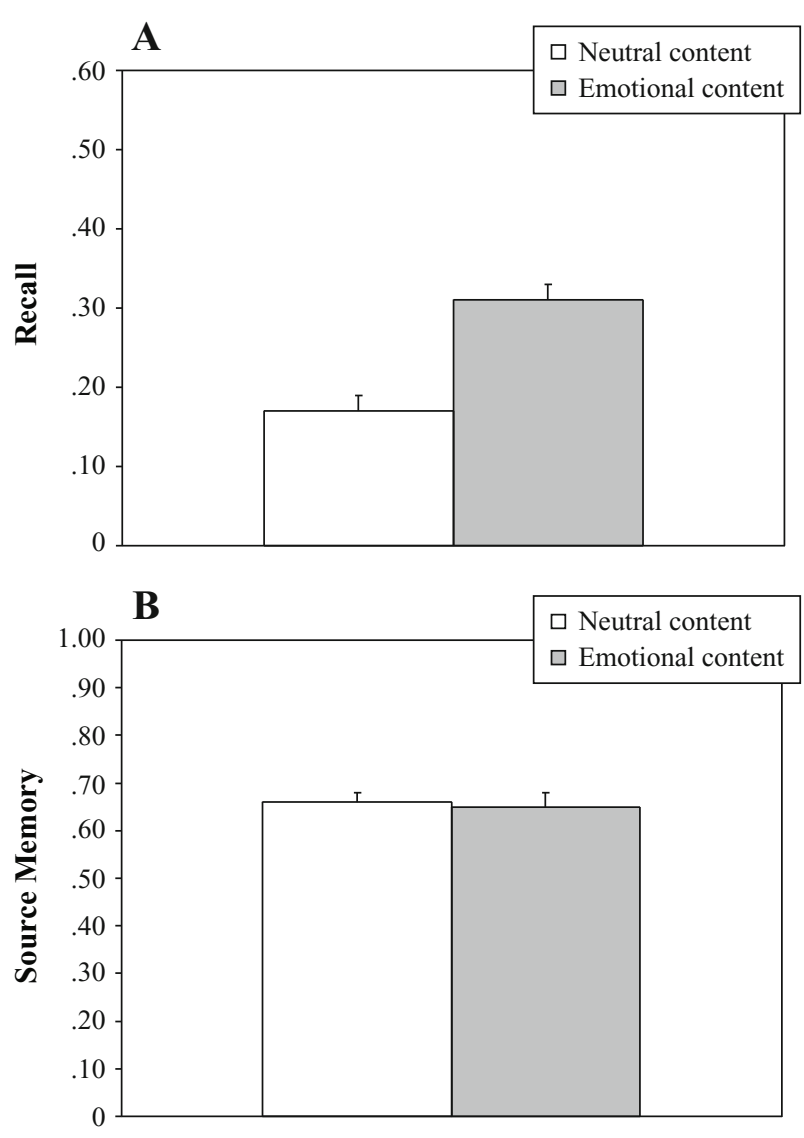

Figure 1. Item (A) and source (B) memory in Experiment 2A $($ mean $+S E)$. 
Table 3

Item and Source Memory Rates in Experiment 2B

\begin{tabular}{|c|c|c|c|c|c|c|c|c|}
\hline \multirow[b]{3}{*}{ Items } & \multicolumn{6}{|c|}{ Item Memory } & \multirow{2}{*}{\multicolumn{2}{|c|}{$\begin{array}{l}\text { Source } \\
\text { Memory }\end{array}$}} \\
\hline & \multicolumn{2}{|c|}{ Hits } & \multicolumn{2}{|c|}{ FAs } & \multicolumn{2}{|c|}{ Hits - FAs } & & \\
\hline & $M$ & $\overline{S D}$ & $\bar{M}$ & $\overline{S D}$ & $M$ & $S D$ & $\bar{M}$ & $S D$ \\
\hline Neutral & .93 & .08 & .04 & .07 & .90 & .08 & .65 & .17 \\
\hline Emotional & .94 & .09 & .07 & .09 & .87 & .09 & .68 & .21 \\
\hline
\end{tabular}

Note-FA, false alarm.

\section{EXPERIMENT 2B}

We again attempted to replicate Doerksen and Shimamura (2001) and Kensinger and Corkin (2003), this time making three changes so that our experiment would match theirs more closely: We used a single, intentional, study phase, inserted a 5-min delay between study and test, and combined the item and the source memory tests into one.

\section{Method}

Participants. Twenty-three young adults (age, $M=18.26$ years, $S D=0.54$; education, $M=12.13$ years, $S D=0.34$ ) were recruited from undergraduate psychology classes at the University of Arizona.

Materials and Procedure. The materials were identical to those in Experiment 2A. The procedure was also the same, with three exceptions. First, encoding was intentional, rather than incidental; the participants were instructed to remember each word and the color in which it had been presented, because they would be tested for this information later. Second, there was a brief (approximately 5-min) delay between study and test phases, during which the participants performed the Mental Arithmetic subtest of the WAIS-R (1981). Finally, the item and the source tests were combined into one, on which the participants read a list of words (half old, half new) and chose from three options for each word: new, old and studied in purple, or old and studied in orange.

\section{Results}

Table 3 shows hit, false alarm, and corrected recognition rates (item hits minus false alarms) for item memory, as well as the proportion of item hits for which the source was also correctly chosen. Within-subjects $t$ tests were conducted, comparing memory for the neutral items with memory for the emotional items. In item recognition, there was no difference between the emotional and the neutral words in the hit or corrected recognition rates, although the false alarm rate was higher for emotional than for neutral foils $[t(22)=$ $2.21, p=.04]$. Note, however, that the hit rates for both kinds of stimuli were near ceiling. More important, source memory was also equivalent between the emotional $(M=$ $.68)$ and the neutral $(M=.65$; chance $=.50)$ words $(t<1)$, even though the scores were well above floor.

\section{Discussion}

In Experiment 2, we conformed more closely to the method reported by Doerksen and Shimamura (2001) and Kensinger and Corkin (2003). Like them, we showed that emotional content enhanced item memory (in Experiment $2 \mathrm{~A}$; in $2 \mathrm{~B}$, performance was too close to the ceiling to see an effect). Unlike them, however, we did not find a significant effect of emotional content on source memory. Given three experiments across 119 participants (using group sizes comparable to those in other studies in the literature), we were fairly confident in our failure to replicate the emotion effect on source memory.

The fact that older adults remained impaired in source memory for emotional stimuli (in Experiment 1), whereas they were unimpaired in FM-arguably a type of source memory-led us to consider other ways in which FM events might differ from laboratory experiments. One potentially important difference between naturalistic emotional events and the laboratory experience may involve the emotionality of the source. When information about a flashbulb event in the real world is conveyed, the source is likely to be emotional (e.g., when a student enters a classroom and announces "The President has been shot!"). In Experiment 1, although the words were emotional, they were spoken in a relatively neutral tone of voice. This neutral tone may have reduced the emotionality of the overall experience, or reduced the likelihood that the source would be integrated with the item. In Experiment 3, we therefore manipulated the emotionality of the sources, as well as the emotionality of the items.

\section{EXPERIMENT 3A}

Because source memory in older adults was close to the floor in Experiment 1, we decided to use sentences, instead of single words, as stimuli here. Sentences convey more acoustic information about the speaker than do single words, making speaker identification easier (e.g., Cook \& Wilding, 1997). We also expected that sentences would yield much greater agreement between the normative and the subjective ratings of emotionality. In this experiment, we varied the emotional tone of the speakers (emotional or neutral), crossing this variable with the type of sentence used (emotional vs. neutral). We expected once again that the emotional content of the stimuli would benefit item memory for both young and older adults but would not affect source memory. The effect of emotional tone on item and source memory, however, was an empirical question. If the emotional tone of voice enhanced the emotionality of the sentences, it might benefit item memory. On the other hand, the effect of emotional tone might benefit source memory disproportionately: The emotionality of the voice might draw attention to the voice-sentence pairing, increasing the likelihood that item and source would be well integrated during encoding, thereby enhancing source memory. If older adults are less likely than young adults to integrate item and source at encoding (Glisky et al., 2001), emotional tone might be particularly beneficial for the older group. When the tone of voice was neutral, however (as in Experiment 1), attention might be drawn to the emotional items at the expense of the source in the older adults.

\section{Method}

Participants. Sixty-four young adults (age, $M=19.73$ years, $S D=3.96$; education, $M=12.98$ years, $S D=1.01$ ) were recruited from undergraduate psychology classes at the University of Arizona. 
Testing was discontinued with 3 additional participants, 2 who failed to follow instructions and 1 who did not understand many of the sentences during the first study phase.

Thirty-two older adults were also recruited (age, $M=74.66$ years, $S D=5.97$; education, $M=15.66$ years, $S D=2.46$ ) from our laboratory pool and were paid $\$ 6 / \mathrm{h}$ to participate. All were community dwelling, and none reported drug or alcohol abuse or neurological or psychiatric illness (including depression and dementia). All reported good hearing, were able to carry out a telephone conversation without difficulty during recruitment, and were able to repeat a sample sentence played at the beginning of the session.

Materials. One hundred sixty-eight sentences were selected from a pool created by Maratos and Rugg (2001). Because most of the words used in our previous experiments were negative, as were most of the highly emotional sentences in the Maratos and Rugg pool, only negative sentences were chosen for the emotional set here. The emotional (i.e., negative) and neutral sentences were rated in a pilot study for pleasure (from $1=$ very low to $9=$ very high), arousal (from $1=$ very low to $9=$ very high), and concreteness (from $1=$ very concrete to $9=$ very abstract). Half of the sentences were chosen to be emotional (i.e., those that obtained the highest ratings of arousal and the lowest ratings of pleasure; e.g., The aircraft exploded and everyone on board was burned to death and He electrocuted her by throwing a television into her bath), and the other half were neutral (i.e., those that obtained the lowest ratings of arousal and neutral ratings of pleasure; e.g., She used to take a vitamin in the morning with some water and The apartment was in the town center).

The sentences were divided into three groups of 56 (half emotional and half neutral). ANOVAs showed that the sets of emotional sentences were rated as more arousing $(M \mathrm{~s}=6.68,6.88$, and 7.04 out of 9$)$ than were the neutral ones $(M \mathrm{~s}=1.16,1.20$, and 1.36 out of 9$)[F(1,162)=$ $4,348.36, p<.001]$. The emotional sentence lists were also rated as more negative $(M \mathrm{~s}=1.82,1.68$, and 1.75 out of 9$)$ than were the neutral lists $(M \mathrm{~s}=5.02,5.00$, and 4.98 out of 9$)[F(1,162)=2,880.86$, $p<.001]$. The groups of sentences were similar in length and ratings of concreteness. One set of 56 sentences was used as the distractor list for the item memory test. The other two sets were used as target lists, counterbalanced to appear equally often in the item and the source phases. All the sentences were recorded by a man and a woman (both amateur actors), using Goldwave software (2002) on a personal computer. Each was recorded in a neutral tone of voice and also in a negative emotional tone (we had the speakers alternate between emotional and neutral sentences and between emotional and neutral tones of voice during recording). For the emotional items, the speakers used an emotional tone that matched the content of the sentence. For the neutral items, the speakers used an emotional tone that was negative.
Procedure. The stimuli were presented auditorily over loudspeakers, using a personal computer. After volume adjustment using a sample sentence, three separate study-test blocks were administered: two for source memory and the other for item memory. In all cases, source memory was examined first (as in Experiment 1).

Source memory was tested in two study-test blocks. In the study phase, the participants were told that they would hear several sentences, some intended to evoke an emotional response, but others not. They rated the content of each sentence by pressing the appropriate key, either $E$ for emotional or $N$ for neutral. They studied 28 sentences, half emotional and half neutral, randomly mixed; half of each type of sentence were spoken by the male voice, and the other half by the female voice. Four additional sentences were presented ( 2 at the beginning and 2 at the end of the study list) but were not analyzed, to minimize primacy and recency effects.

Source memory was tested immediately thereafter, in a 2-AFC format. Each studied sentence was replayed in the original voice that had spoken it (the target) and in the opposite-sex voice (the distractor), in a series of randomly ordered trials. The tone of voice for each target was the same as that at study. In half the trials, the target was presented before the distractor, and in the other half, the order was reversed. The participants indicated by a keypress whether the first or the second voice had spoken the sentence originally.

Once the first source memory test was finished, the other source memory study-test block was administered using 28 new sentences. The only difference between the two blocks was that in one, all of the sentences were presented in a neutral tone of voice, whereas in the other, they were presented in a negative emotional tone. The order of these blocks and whether the sentences appeared in one block or the other was counterbalanced.

In the item memory study phase, the remaining 56 target sentences (plus 4 buffer sentences) were used. As in the source memory phase, half of the sentences were emotional, and half were neutral; half of each kind of sentence were in a neutral tone of voice, and half in a negative emotional tone. Study instructions were the same as those for the source memory phase. The item memory test involved a yes/no decision to the 56 target sentences (the tone of voice for each target was the same as at study), randomly mixed with 56 distractor sentences, in which content (neutral or emotional) and tone (neutral or emotional) were crossed the same way as for the targets.

\section{Results}

The mean proportion of stimuli rated as emotional is shown in Table 4 for each age group. For the item memory study phase, a 2 (age group: young or older) $\times 2$ (sentence

Table 4

Proportions of Items Rated As "Emotional" by Young and Older Adults in Experiment 3A

\begin{tabular}{|c|c|c|c|c|}
\hline \multirow[b]{2}{*}{ Stimuli } & \multicolumn{2}{|c|}{ Young Adults } & \multicolumn{2}{|c|}{ Older Adults } \\
\hline & $M$ & $S D$ & $M$ & $S D$ \\
\hline \multicolumn{5}{|c|}{ Item Memory } \\
\hline \multicolumn{5}{|l|}{ Neutral tone } \\
\hline Neutral items & .02 & .07 & .01 & .03 \\
\hline Emotional items & .82 & .29 & .90 & .24 \\
\hline \multicolumn{5}{|l|}{ Emotional tone } \\
\hline Neutral items & .12 & .25 & .03 & .07 \\
\hline Emotional items & .94 & .09 & .96 & .07 \\
\hline \multicolumn{5}{|c|}{ Source Memory } \\
\hline \multicolumn{5}{|l|}{ Neutral tone } \\
\hline Neutral items & .04 & .09 & .01 & .02 \\
\hline Emotional items & .83 & .25 & .96 & .07 \\
\hline \multicolumn{5}{|l|}{ Emotional tone } \\
\hline Neutral items & .11 & .16 & .02 & .04 \\
\hline Emotional items & .90 & .14 & .92 & .10 \\
\hline
\end{tabular}


Table 5

Item Hit and False Alarm (FA) Rates in Young and Older Adults in Experiment 3A

\begin{tabular}{|c|c|c|c|c|c|c|c|c|}
\hline \multirow[b]{3}{*}{ Stimuli } & \multicolumn{4}{|c|}{ Young Adults } & \multicolumn{4}{|c|}{ Older Adults } \\
\hline & \multicolumn{2}{|c|}{ Hits } & \multicolumn{2}{|c|}{ FAs } & \multicolumn{2}{|c|}{ Hits } & \multicolumn{2}{|c|}{ FAs } \\
\hline & $M$ & $S D$ & $M$ & $S D$ & $M$ & $S D$ & $M$ & $S D$ \\
\hline \multicolumn{9}{|l|}{ Neutral tone } \\
\hline Neutral items & .85 & .15 & .11 & .09 & .78 & .15 & .10 & .10 \\
\hline Emotional items & .90 & .13 & .10 & .09 & .90 & .11 & .14 & .11 \\
\hline \multicolumn{9}{|l|}{ Emotional tone } \\
\hline Neutral items & .84 & .13 & .10 & .09 & .78 & .17 & .09 & .09 \\
\hline Emotional items & .92 & .09 & .08 & .10 & .87 & .13 & .13 & .11 \\
\hline
\end{tabular}

type: emotional or neutral) $\times 2$ (tone of voice: emotional or neutral) mixed ANOVA showed that the sentences were more likely to be labeled as emotional when they were emotional than when they were neutral $[F(1,92)=1,151.67$, $\left.M S_{\mathrm{e}}=0.05, p<.001\right]$ and, also, when the tone of voice was emotional versus neutral $\left[F=9.73, M S_{\mathrm{e}}=0.05, p=.002\right]$. No other main effects or interactions were significant.

An analysis of the source memory ratings showed a similar pattern, with ratings of emotionality influenced both by the content of the sentence $\left[F(1,90)=1,795.57, M S_{\mathrm{e}}=\right.$ $0.03, p<.001]$ and by tone of voice $\left(F=8.06, M S_{\mathrm{e}}=\right.$ $0.02, p=.006)$. The only other significant pattern was an interaction between content of the sentence and age group $\left(F=8.06, M S_{\mathrm{e}}=0.01, p=.006\right)$, with older adults showing greater differentiation between emotional and neutral sentences in their ratings than did the young adults.

Item memory hits and false alarms for the four kinds of stimuli are shown in Table 5 and were examined using 2 (age group: young or older) $\times 2$ (sentence type: emotional or neutral) $\times 2$ (tone of voice: emotional or neutral) mixed ANOVAs. Hit rates were higher in the young adults than in the older adults $\left[F(1,93)=4.11, M S_{\mathrm{e}}=0.04, p=.05\right]$ and were higher for emotional sentences than for neutral ones $\left(F=64.51, M S_{\mathrm{e}}=0.009, p=.001\right.$; no other main effects or interactions were significant). For false alarms, the only significant effect was the interaction between age group and sentence type $\left[F(1,93)=8.63, M S_{\mathrm{e}}=0.006\right.$, $p=.004]$. Analysis of the simple main effects indicated that the older adults made reliably more false alarms to emotional than to neutral sentences $[F(1,31)=6.60$, $\left.M S_{\mathrm{e}}=0.006, p=.02\right]$, whereas in the young adults there was no difference.

A similar analysis was also performed using the corrected item recognition scores (hits minus false alarms), shown in Figures $2 \mathrm{~A}$ and $2 \mathrm{~B}$. The young group (Figure $2 \mathrm{~A}$ ) remembered more sentences than did the older group [Figure 2B; $F(1,93)=4.06, M S_{\mathrm{e}}=0.07, p=.03$ ] Recognition of the emotional sentences $(M=.82)$ was superior to recognition of the neutral sentences $(M=.73)$ $\left[F(1,93)=33.03, M S_{\mathrm{e}}=0.02, p<.001\right]$. The tone in which the sentences were spoken had no bearing on item memory $(F<1)$. None of the interactions among sentence type, tone of voice, and age group was significant. ${ }^{2}$

Source memory for the four kinds of stimuli is shown in Figures 3A and 3B. Data are presented and were ana- lyzed only for the first source memory test for each individual, which was uncontaminated by any possible carryover effects. (A preliminary analysis showed an effect of test phase order that interacted with tone of voice, suggesting asymmetric carryover effects from the first to the second source memory test. We therefore analyzed the data from the first source memory test only, using a between-subjects comparison of tone of voice.) A 2 (age group: young or older) $\times 2$ (sentence type: emotional or neutral) $\times 2$ (tone of voice: emotional or neutral) mixed ANOVA indicated that source memory was better in the young people than in the older people $[F(1,92)=14.64$, $\left.M S_{\mathrm{e}}=0.02, p<.001\right]$. Source memory for the emotional sentences $(M=.65)$ was slightly worse than that for the neutral sentences, although not significantly so $(M=.68)$ $\left[F(1,92)=3.20, M S_{\mathrm{e}}=0.02, p=.08\right]$. However, source memory was reliably better when sentences were spoken in an emotional tone $(M=.72)$ than when spoken in a neutral tone $(M=.62)\left[F(1,92)=14.27, M S_{\mathrm{e}}=0.02\right.$, $p<.001]$, and these effects did not interact with age. No other interactions were significant.

Pearson correlations were computed in each age group for each of the four kinds of stimuli to assess the extent to which performance on the item and the source memory tests was related. In neither age group were any of these significant $(r \mathrm{~s}<|.29|)$.

\section{Discussion}

This experiment contrasted the effects of emotional content and emotional source (tone of voice) on memory. Item memory, in both young people and older adults, was better for the emotional sentences than for the neutral sentences (as was expected) but was not significantly influenced by the tone in which the sentences were spoken. Source memory showed the opposite pattern: It was not sensitive to the emotional content of the sentence but was significantly better when the tone of voice was emotional than when it was neutral, in both young and older people.

Once again, we failed to find any effect of emotional content on source memory, in either young or older adults. Because there also appeared to be a double dissociation (emotional sentences enhanced item memory but not source memory, whereas emotional tone of voice enhanced source memory but not item memory), we wanted to explore these effects further. We reconducted the study 
with a new group of participants and modified the procedure so that the item and the source memory tests were administered in the same way.

\section{EXPERIMENT 3B}

In Experiment 3B, we counterbalanced the order of source and item study-test blocks, to address the possibility that the differential effects of emotion found in Experiment 3A were the product of order effects or changes in strategy. We also altered source presentation so that the formats of the source and the item study-test blocks were identical.

\section{Method}

Participants. Thirty-two young adults (age, $M=19.28$ years, $S D=1.59$; education, $M=12.78$ years, $S D=0.66$ ) and 32 older adults (age, $M=77.65$ years, $S D=5.73$; education, $M=15.22$ years, $S D=2.66$ ) were recruited from the same participant pools as those in Experiment $3 \mathrm{~A}$ and according to the same criteria. Data from 2 ad- ditional young and 3 additional older participants were excluded (because of computer malfunction or failure to understand instructions).

Materials and Procedure. The materials were identical to those used in Experiment 3A. The procedure was also the same, but with two exceptions. First, the source study lists were not blocked by tone but were mixed, so that half of the sentences of each type were spoken in an emotional tone of voice and half were spoken in a neutral tone. The sentences were counterbalanced so as to appear equally often in each study-test block. Thus, the makeup of the source blocks was identical to that of the item block. Second, the order in which the participants completed source and item blocks was counterbalanced, so that half of all the participants performed the source study-test blocks first, whereas the other half of the participants performed the item study-test blocks first.

\section{Results}

The mean proportion of stimuli rated as emotional is shown in Table 6 for each age group. For the item memory study phase, a 2 (age group: young or older) $\times 2$ (sentence type: emotional or neutral) $\times 2$ (tone of voice: emotional or
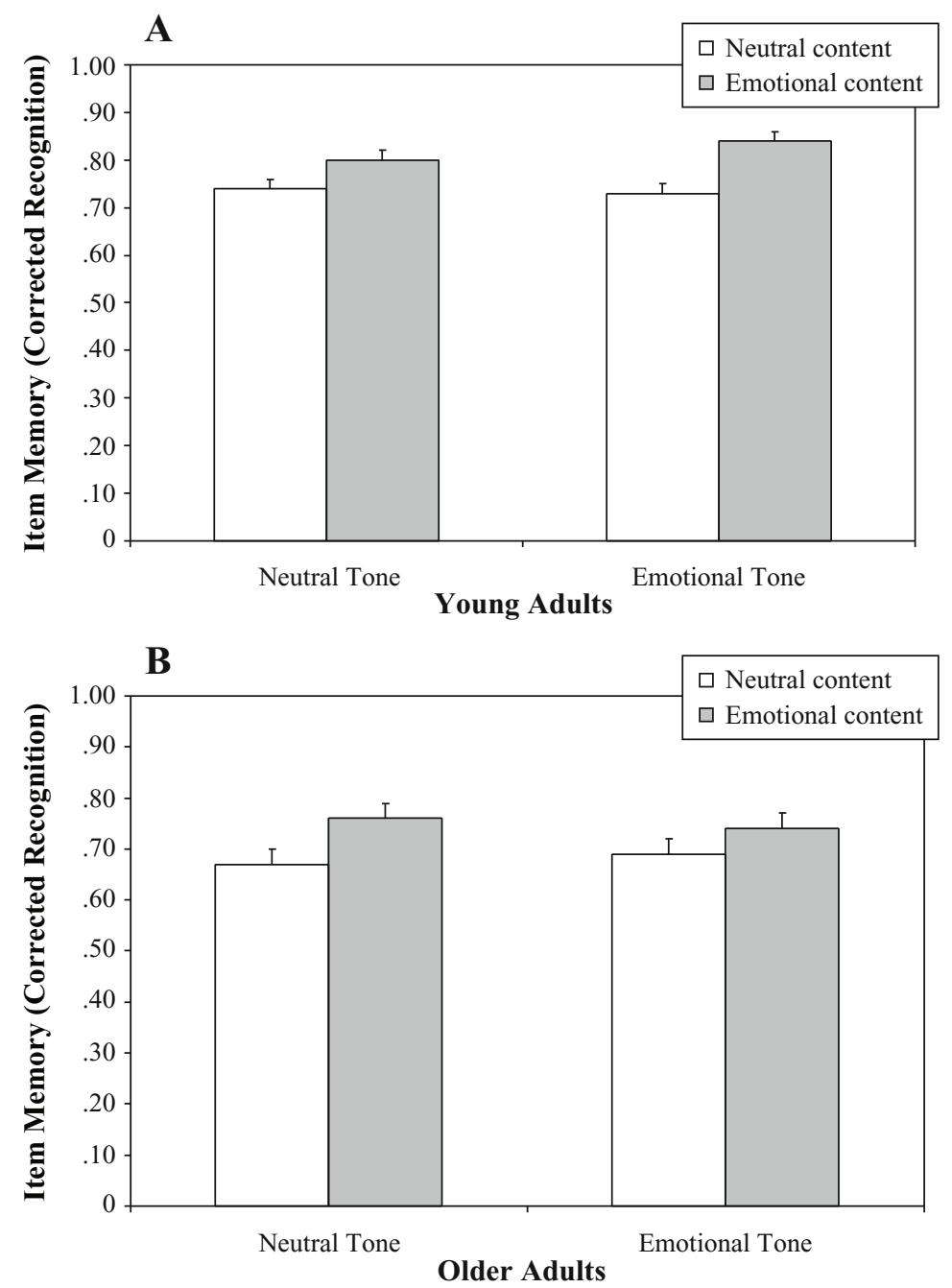

Figure 2. Item memory in (A) young and (B) older adults in Experiment 3A $($ mean $+S E)$. 

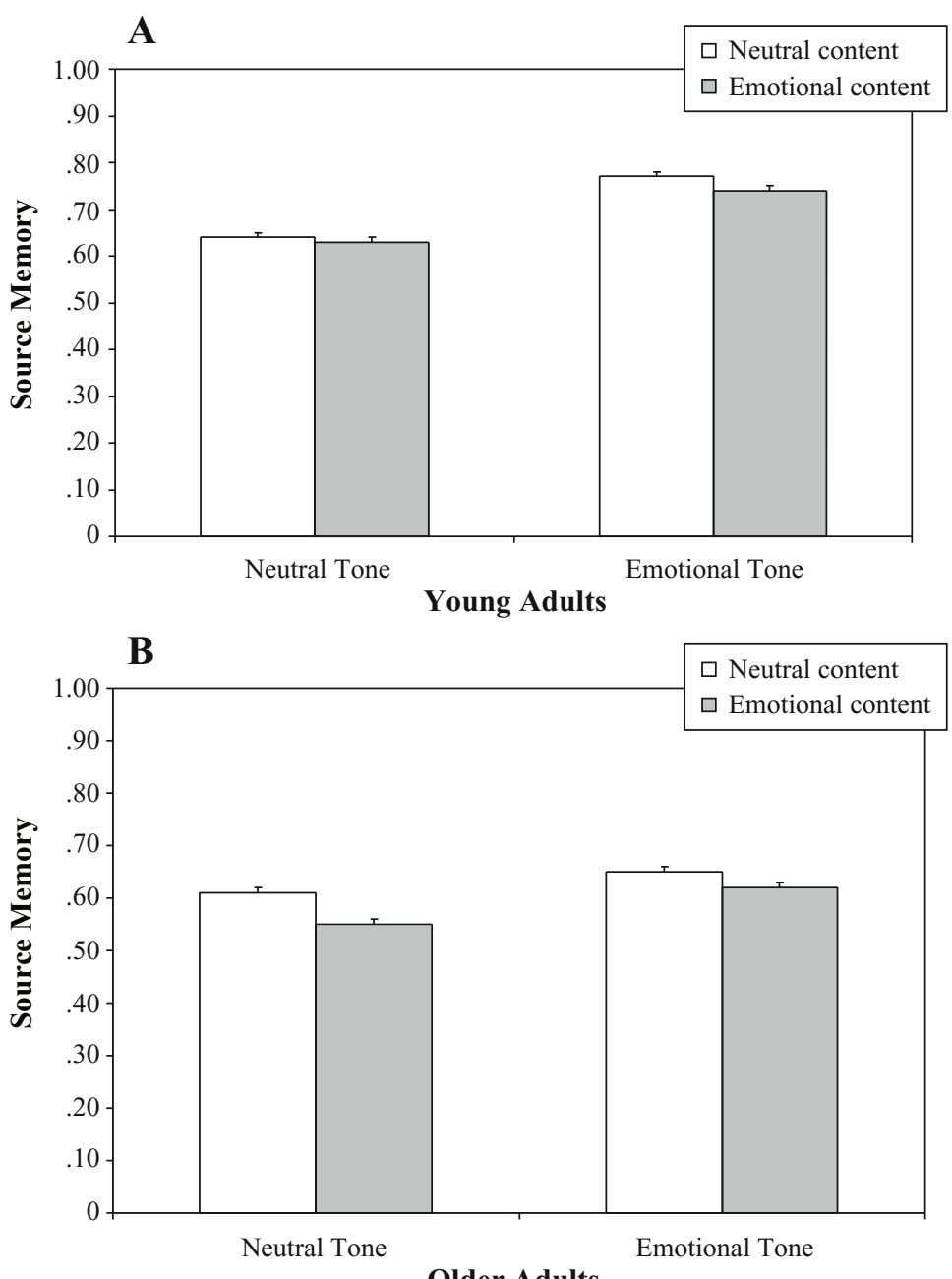

Older Adults

Figure 3. Source memory in (A) young and (B) older adults in Experiment 3A $($ mean $+S E)$.

neutral) mixed ANOVA showed that sentences were more likely to be labeled as emotional when the sentences were emotional than when they were neutral $[F(1,62)=7,470.35$, $\left.M S_{\mathrm{e}}=0.01, p<.001\right]$ and also when the tone of voice was emotional versus neutral $\left(F=18.38, M S_{\mathrm{e}}=0.01, p<\right.$ $.001)$. Although there was no main effect of age $(F<1)$, there were significant interactions between sentence type and age group $\left(F=27.25, M S_{\mathrm{e}}=0.01, p<.001\right)$ and between tone of voice and age group $\left(F=17.50, M S_{\mathrm{e}}=0.01\right.$, $p<.001)$. These interactions occurred because the young people's ratings of the emotionality of the sentences were affected by the tone of voice, whereas the older people were insensitive to the tone. Thus, the younger people rated neutral items as more emotional when they were presented in an emotional tone and rated emotional items as less emotional when they were presented in a neutral tone. The older adults rated neutral and emotional sentences accurately and were unaffected by the tone of voice.

An analysis of the ratings in the source memory study blocks showed an identical pattern, and the ratings lend themselves to the same interpretation. Ratings of emotionality were influenced both by the content of the sentence $\left[F(1,62)=5,033.53, M S_{\mathrm{e}}=0.01, p<.001\right]$ and by tone of voice $\left(F=16.46, M S_{\mathrm{e}}=0.01, p<.001\right)$. Although there was no main effect of age $(F<1)$, there were significant interactions between sentence type and age group $\left(F=44.69, M S_{\mathrm{e}}=0.01, p<.001\right)$ and between tone of voice and age group $\left(F=12.79, M S_{\mathrm{e}}=0.01, p<.001\right)$.

Item memory hits and false alarms for the four kinds of stimuli are shown in Table 7 and were examined using 2 (age group: young or older) $\times 2$ (sentence type: emotional or neutral) $\times 2$ (tone of voice: emotional or neutral) mixed ANOVAs. Hit rates were higher in the young adults than in the older adults $\left[F(1,62)=4.62, M S_{\mathrm{e}}=0.06, p=.04\right]$ and were higher for emotional sentences than for neutral ones $\left(F=53.70, M S_{\mathrm{e}}=0.01, p<.001\right)$. Hit rates were also higher for the sentences spoken in an emotional tone than for those spoken in a neutral tone $\left(F=7.66, M S_{\mathrm{e}}=\right.$ $0.01, p=.007)$, and there was a significant interaction between tone and content $\left(F=5.55, M S_{\mathrm{e}}=0.01, p=\right.$ 
Table 6

Proportions of Items Rated As "Emotional" by Young and Older Adults in Experiment 3B

\begin{tabular}{|c|c|c|c|c|}
\hline \multirow[b]{2}{*}{ Stimuli } & \multicolumn{2}{|c|}{ Young Adults } & \multicolumn{2}{|c|}{ Older Adults } \\
\hline & $M$ & $S D$ & $M$ & $S D$ \\
\hline \multicolumn{5}{|c|}{ Item Memory } \\
\hline \multicolumn{5}{|l|}{ Neutral tone } \\
\hline Neutral items & .00 & .02 & .02 & .03 \\
\hline Emotional items & .84 & .10 & .94 & .06 \\
\hline \multicolumn{5}{|l|}{ Emotional tone } \\
\hline Neutral items & .12 & .15 & .02 & .04 \\
\hline Emotional items & .90 & .09 & .93 & .07 \\
\hline \multicolumn{5}{|c|}{ Source Memory } \\
\hline \multicolumn{5}{|l|}{ Neutral tone } \\
\hline Neutral items & .03 & .08 & .03 & .08 \\
\hline Emotional items & .81 & .18 & .92 & .06 \\
\hline \multicolumn{5}{|l|}{ Emotional tone } \\
\hline Neutral items & .16 & .15 & .02 & .03 \\
\hline Emotional items & .89 & .09 & .95 & .04 \\
\hline
\end{tabular}

.02). The interaction was due to the fact that for the neutral sentences, an emotional tone led to a higher hit rate than did a neutral tone $(M \mathrm{~s}=.81$ and $.75 ; t=3.13, p=.003)$, whereas for the emotional sentences, there was no difference between the emotional and the neutral tones $(M \mathrm{~s}=$ .87 and .86). False alarms were lower in the young than in the older adults $\left[F(1,62)=10.31, M S_{\mathrm{e}}=0.03, p=.002\right]$ and were higher for emotional than for neutral content $\left(F=5.25, M S_{\mathrm{e}}=0.008, p=.03\right)$. No other main effects or interactions were significant.

A similar analysis was performed on corrected item recognition scores (hits minus false alarms), shown in Figures $4 \mathrm{~A}$ and 4B. The young people (Figure 4A) remembered more sentences than did the older people [Figure 4B; $\left.F(1,62)=15.62, M S_{\mathrm{e}}=0.07, p<.001\right]$. Recognition of the emotional sentences $(M=.77)$ was superior to recognition of the neutral sentences $(M=.71)(F=$ $\left.13.42, M S_{\mathrm{e}}=0.09, p=.001\right)$. Contrary to the findings in Experiment $3 \mathrm{~A}$, the tone in which the sentences were spoken had a small but significant effect: Memory was better for the sentences spoken in an emotional tone $(M=.76)$ than for those spoken in a neutral tone $(M=.73)(F=$ $\left.7.61, M S_{\mathrm{e}}=0.01, p=.008\right)$. None of the interactions was significant.

Source memory for the four kinds of stimuli is shown in Figures 5A and 5B. Source memory was analyzed using a 2 (age group: young or older) $\times 2$ (sentence type: emotional or neutral) $\times 2$ (tone of voice: emotional or neutral) mixed ANOVA, in which both sentence type and tone of voice were within-subjects variables. As in Experiment $3 \mathrm{~A}$, source memory was better in the young people than in the older people $\left[F(1,62)=50.19, M S_{\mathrm{e}}=0.03\right.$, $p<.001]$ and was equivalent for emotional and neutral sentences $(F<1)$. However, source memory was reliably better when sentences were spoken in an emotional tone than when spoken in a neutral tone $\left(F=16.61, M S_{\mathrm{e}}=\right.$ $0.01, p<.001)$. In this experiment, the interaction between age group and tone was also significant $(F=4.69$, $\left.M S_{\mathrm{e}}=0.01, p=.04\right)$ : Although young people showed a significant advantage in source memory when the tone was emotional versus neutral $(M \mathrm{~s}=.76$ and .67 , respectively; $t=4.32, p<.001)$, the benefit was smaller and not significant in older people $(M \mathrm{~s}=.58$ and .56 , respectively; $t=1.38$, n.s.).

Pearson correlations were computed in each age group for each of the four kinds of stimuli to assess the extent to which performance on the item and the source memory tests was related. In neither age group were any of these significant $(r \mathrm{~s}<|.24|)$.

\section{Discussion}

Once again, item memory was significantly better for emotional than for neutral content, but source memory was not affected by the emotional content of the sentence. This pattern was consistent across young and older adults and replicated the findings of Experiments 1, 2, and 3A.

The manipulation of tone of voice had a different effect from the manipulation of content. When tone of voice was emotional, instead of neutral, there was a small but significant benefit to item memory (an overall increase of approximately $3 \%$ ). This small memory advantage for sentences heard in an emotional tone is likely attributable to the fact that the sentences took on a more emotional meaning when they were read in an emotional way. The ratings suggested that this was especially true in the young group. That is, the young adults were more likely to rate the content of neutral sentences as emotional when the tone of voice was emotional than when it was neutral, but the older people did not show this difference. In item memory, the beneficial effect of tone of voice appeared to occur primarily in the young adults with neutral sentences, as can be seen in Figure 4. The differences between the young and the older adults in ratings and item memory, although small, raise the possibility that young people have an easier time integrating item and source information in memory than do older people.

Our more immediate focus was on source memory, however. We had predicted that an emotional tone would draw attention to the voice-sentence pairing, leading to better integration of item and source information during encoding and, thus, to better source memory. We also thought that this benefit might be greater in older people than in the young, because previous studies that used in-

\section{Table 7}

Item Hit and False Alarm (FA) Rates in Young and Older Adults in Experiment 3B

\begin{tabular}{|c|c|c|c|c|c|c|c|c|}
\hline \multirow[b]{3}{*}{ Stimuli } & \multicolumn{4}{|c|}{ Young Adults } & \multicolumn{4}{|c|}{ Older Adults } \\
\hline & \multicolumn{2}{|c|}{ Hits } & \multicolumn{2}{|c|}{ FAs } & \multicolumn{2}{|c|}{ Hits } & \multicolumn{2}{|c|}{ FAs } \\
\hline & $M$ & $S D$ & $M$ & $S D$ & $M$ & $S D$ & $M$ & $S D$ \\
\hline \multicolumn{9}{|l|}{ Neutral tone } \\
\hline Neutral items & .78 & .13 & .04 & .06 & .71 & .18 & .09 & .12 \\
\hline Emotional items & .89 & .12 & .06 & .06 & .83 & .16 & .14 & .14 \\
\hline \multicolumn{9}{|l|}{ Emotional tone } \\
\hline Neutral items & .87 & .14 & .04 & .06 & .76 & .19 & .09 & .10 \\
\hline Emotional items & .89 & .13 & .06 & .06 & .85 & .15 & .12 & .14 \\
\hline
\end{tabular}


structional manipulations to help participants integrate item and source information at encoding have shown a greater benefit for older adults than for young adults (e.g., Glisky et al., 2001; although note that faulty encoding may not be the only cause of source memory problems in older adults; see Multhaup, 1995). If anything, however, we found the opposite: Emotional tone of voice benefited source memory to a greater extent in the young than in the older group. The emotionality of the voice did not appear to increase the likelihood of older adults' integrating item and source information at encoding.

\section{GENERAL DISCUSSION}

In this article, we have explored the relations among item and source memory, emotion, and aging. The main goal of these experiments was to discover whether item and source memory are affected in the same way by emotion and whether the age-related deficit usually observed in source memory is affected by using emotional materials. These points will be discussed in turn below.

\section{Memory for Emotional Items Is Better Than Memory for Neutral Items}

Consistent with the existing literature, we found that emotional stimuli (both words and sentences) were easier to remember (in both recall and recognition) than neutral ones. The emotional and neutral word lists differed in valence, in addition to arousal, but most studies have indicated that item memory is influenced more by the latter than by the former (e.g., Bradley et al., 1992). The emotional and neutral item lists were equated on several variables, including length, frequency, and abstractness, making it unlikely that aspects of the stimuli other than their emotionality could account for the differences in memory across lists. One additional factor that we did not control for was the semantic interrelatedness of the items within each list. Emotional items usually have more in
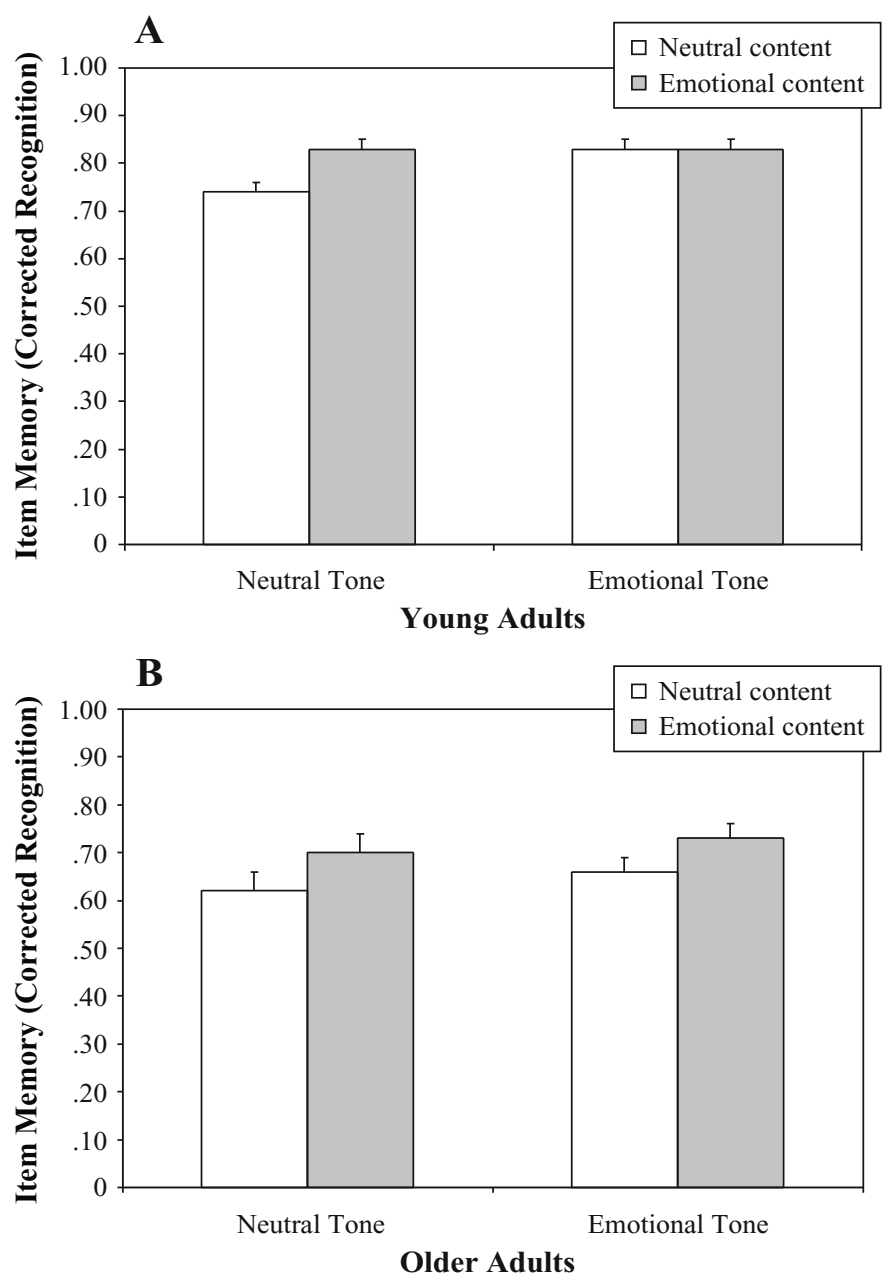

Figure 4. Item memory in (A) young and (B) older adults in Experiment $3 B$ (mean $+S E)$. 

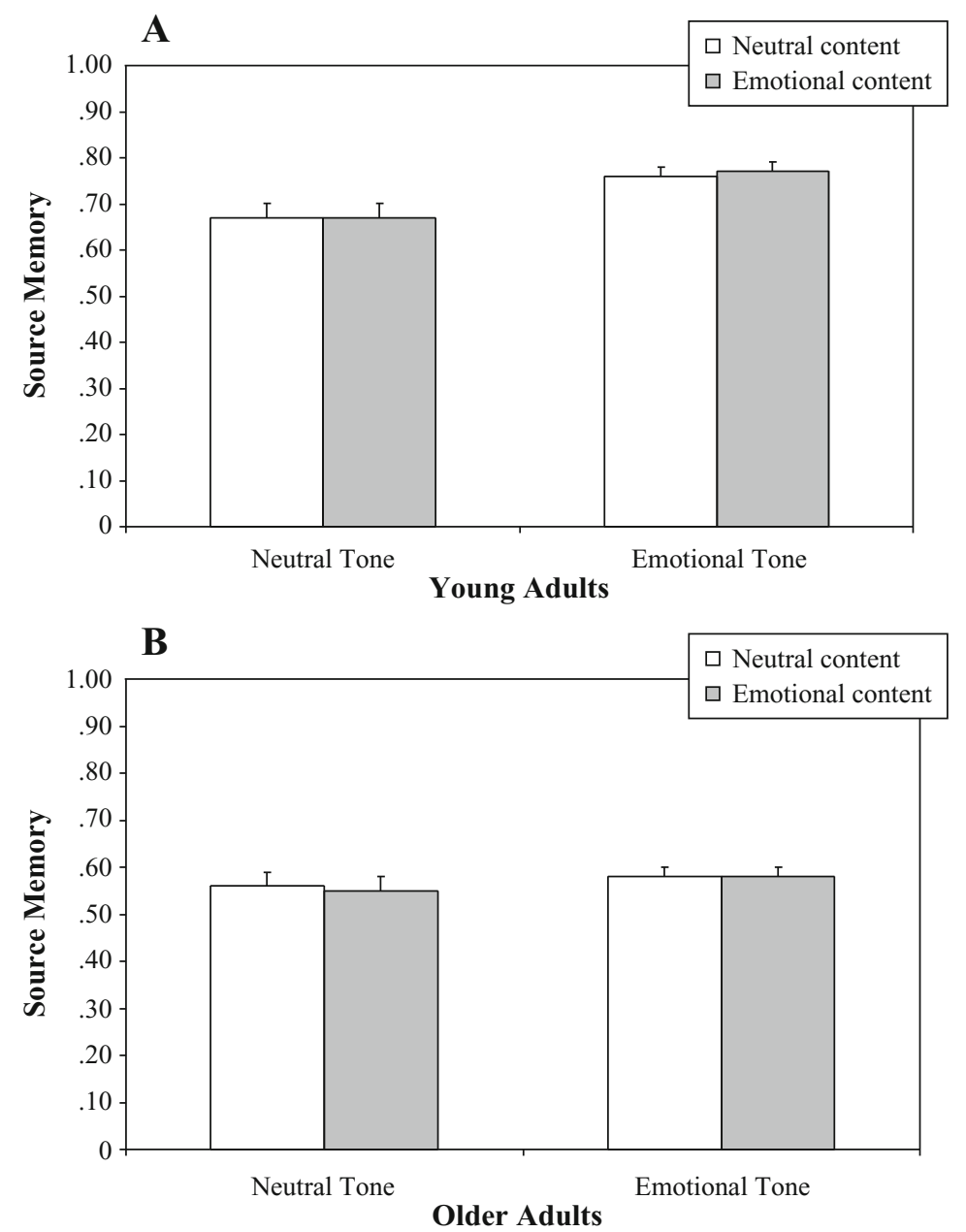

Figure 5. Source memory in (A) young and (B) older adults in Experiment 3B $($ mean $+S E)$.

common with one another than do neutral items, which can contribute to the superior memory for the former (e.g., Talmi \& Moscovitch, 2004). Yet regardless of the extent to which semantic relatedness (or any other factor beyond emotionality per se) may have contributed to the item memory benefit, it had no effect on source memory.

\section{Enhancement of Item Memory by Emotional Content Is Similar in Young and Older Adults}

Despite an age-related decline in performance overall, the emotion advantage in item memory was similar in the two age groups (Experiments 1 and 3), consistent with recent reports (e.g., Denberg et al., 2003; Kensinger et al., 2005; Leigland et al., 2004; Yoder \& Elias, 1987). ${ }^{3}$ Note that in the present study, we used mostly negative emotional stimuli, because they are more likely than positive ones to be highly arousing, and arousal has been shown in young people to be the major contributor to the emotional memory advantage (Bradley et al., 1992). Some researchers, however, have found a shift in older adults' emotional memories from negative to positive stimuli (e.g., Charles et al., 2003). It is possible, therefore, that older adults might have shown an even greater benefit of emotion on item memory than young people if we had used positively valenced materials (e.g., Charles et al., 2003; for a review, see Mather \& Carstensen, 2005). Whether this is also the case for source memory could be examined in future experiments.

The similar memory advantage shown by both age groups for negative materials in the present study suggests that the emotion enhancement mechanism involves cognitive or neural processes that remain relatively intact during aging. One candidate mechanism involves the amygdala, which has been implicated in the emotional enhancement of memory in human lesion and neuroimaging studies (for reviews, see Buchanan \& Adolphs, 2002; Hamann, 2001). Although the volume of the amygdala may decline somewhat in aging (e.g., Herzog \& Kemper, 1980; Jack et al., 1997; Smith et al., 1999), it may continue to function relatively normally in healthy older adults (for similar arguments, see Davidson \& Glisky, 2002; Denberg et al., 2003; Hedden \& Gabrieli, 2004). 


\section{No Reliable Effect of Emotional Content on Source Memory}

In contrast to the robust enhancement of item memory by emotional content, there was little evidence for a relation between source memory and emotional content (using group sizes that were comparable to those in other studies in the literature). Only in Experiment 1 was there a suggestion that emotional, as compared with neutral, content might be related to better source memory in young adults, and when participants' subjective ratings were used to divide words into the emotional and neutral categories, this effect disappeared. As well, the findings of emotional content's benefiting source memory that were reported by Doerksen and Shimamura (2001) and Kensinger and Corkin (2003) could not be replicated in this study (Experiments 2 and 3 ) or in recent studies by Shimamura (e.g., 2003). The present study provides evidence against the idea that item and source memory are affected similarly by emotion and, thereby, fails to support the tick rate hypothesis (e.g., Kahneman, 1973; Revelle \& Loftus, 1992).

On the other hand, there was also little evidence of a trade-off between item and source memory to support the hypothesis of Easterbrook (1959; see also Jurica \& Shimamura, 1999, for a possible example of an item-source trade-off in memory, using the generation effect; but see Geghman \& Multhaup, 2004). For example, there was a clear advantage for item memory when content was emotional, relative to neutral; however, there was little effect on source memory as a function of the emotional content of the sentences. If the superior memory for emotional items stems, in part, from their ability to attract attention at encoding, it is not at the expense of memory for the source information. If this were the case, one might predict that as item memory improved, source memory would decline, but this did not occur in any of our experiments. Using emotional items, instead of neutral ones, improved memory for the items themselves but did not significantly impair memory for the associated source information.

One could argue, however, that although the Easterbrook (1959) hypothesis was not supported by the present experiments, it may account for performance in other source memory paradigms, depending on the relation between item and source information. For example, in some paradigms, it may be relatively easy to attend to the item and ignore the source at encoding, such as when the item is a picture of an object and the "source" is another object nearby (e.g., Shimamura, 2003). In such studies, making the item emotional may impair memory for the source by completely drawing attention away from the source object. In other paradigms, it may be more difficult, if not impossible, to segregate item and source information at encoding, such as when the item is a single word and the source is a sentence in which the word is embedded. In those studies, making the item emotional may enhance memory for the source (e.g., Kensinger et al., 2002). The paradigm that we employed, involving words or sentences spoken by voices, may have fallen somewhere between these two extremes, so that the effect of emotional content generally had no effect on the source. Introducing an encoding manipulation that encouraged participants to link item and source information explicitly might reveal a positive effect of emotional content on source memory.

One factor that may determine how emotion affects memory concerns which aspect(s) of an event are perceived as being related to the emotion. For example, Bower (1992; see Macauley, Ryan, \& Eich, 1993) has argued that in order for emotion to have a strong effect on memory, participants must infer a causal link between the emotion and the stimulus or must view the relation between an emotion and some aspect of an accompanying event as relevant. If participants see no relation between emotion and some feature of an event, memory for that feature is unlikely to be enhanced by the emotion. In many paradigms, emotion is more closely linked to item than to source information (e.g., when an emotional picture is shown against a neutral, unrelated background). This may be why item memory is usually better for emotional content, whereas source memory is not.

\section{Effect of Emotional Tone of Voice on Item and Source Memory}

Although emotional content did not benefit source memory, the emotional tone of voice did, although the effect was smaller in older adults (in Experiment 3B). There are at least two possible reasons why emotional tone aided source memory. One is that during encoding, the emotionality of the voice drew attention to the voice-sentence pairing. A second is that making the tone of voice emotional made the sources more distinct and more readily discriminable from one another on the basis of inflection, prosody, pacing, and so forth. Consistent with the latter possibility, Dodson, Holland, and Shimamura (1998) found better source memory when a forced choice test involved two speakers of opposite sexes than when it involved two speakers of the same sex.

This manipulation of emotional tone of voice had a smaller (approximately 3\% in Experiment 3B) and less reliable (no effect in Experiment 3A) impact on item memory. The rating data suggest that sentences may take on a more emotional meaning when they are read in an emotional tone, especially for young people, and emotional interpretation of the sentence may be reflected in enhanced item memory. Older adults appeared unaffected by the tone in their ratings, however, and correspondingly, showed no benefit in item memory. This observation is consistent with previous studies (e.g., Glisky et al., 2001) demonstrating that older adults are less likely than young adults to integrate item and source at study.

\section{Aging and Source Memory}

Source memory was significantly poorer in older adults than in young adults, consistent with previous research (Brown et al., 1995; Ferguson et al., 1992; Henkel et al., 1998; McIntyre \& Craik, 1987; Schacter et al., 1991; Spencer \& Raz, 1994; Trott et al., 1997; for reviews, see 
Prull et al., 2000; Spencer \& Raz, 1995). One possibility that we examined was that emotion would cause an item-source trade-off in older adults' memory, as has previously been found in some studies (e.g., Naveh-Benjamin \& Craik, 1996; for a possible example in young adults, see Jurica \& Shimamura, 1999). In all three experiments in which older adults were tested, however, we found no evidence that enhancement of item memory by emotional content was associated with poorer source memory.

A second possibility was that emotion might attenuate the source memory deficit usually observed in older adults in the laboratory. Because we had found previously that older people were as likely as young to remember when, where, and from whom they had heard about an emotional real-world event (Davidson \& Glisky, 2002; Davidson et al., 2006), we had speculated that emotional arousal might boost or enhance the processes responsible for the encoding of source information, leading to better performance than normally would be expected in older people. The evidence from the present experiments did not support this hypothesis. The older adults did not show superior source memory for emotional than for neutral materials, and for both emotional and neutral stimuli, their source memory performance remained inferior to that of the young group. The only difference between young and older adults that we found with respect to emotion and source memory involved the tone-of-voice manipulation. In Experiment 3B, young people showed a greater advantage in source memory for the emotional tone than older people did. This went against our predictions and did not support the idea that emotionality of source information would benefit older people preferentially by helping them to integrate item and source information at encoding.

In summary, emotional content was consistently better remembered than neutral content, but the benefits of emotional content did not extend to source memory. These effects were identical in young and older adults. Source memory, however, was enhanced by the emotional tone of the source, although this effect was smaller in older adults. Effects of emotional tone on item memory were absent in older adults and inconsistent in young. The differential effects of emotion on item and source memory provide further evidence that these two kinds of memory depend on different mechanisms.

\section{REFERENCES}

Bower, G. H. (1992). How might emotions affect learning? In S.-Å. Christianson (Ed.), Handbook of memory and emotion: Research and theory (pp. 3-31). Hillsdale, NJ: Erlbaum.

Bradley, M. M., Greenwald, M. K., Petry, M. C., \& Lang, P. J. (1992). Remembering pictures: Pleasure and arousal in memory. Journal of Experimental Psychology: Learning, Memory, \& Cognition, 18, 379-390.

BrADLEY, M. M., \& LANG, P. J. (1999). Affective norms for English words $(A N E W)$. Gainesville: University of Florida, NIMH Center for the Study of Emotion and Attention.

Brown, A. S., Jones, E. M., \& Davis, T. L. (1995). Age differences in conversational source monitoring. Psychology \& Aging, 10, 111-122.

Brown, R., \& Kulik, J. (1977). Flashbulb memories. Cognition, 5, 7399.

Buchanan, T. W., \& Adolphs, R. (2002). The role of the human amyg- dala in emotional modulation of long-term declarative memory. In S. Moore \& M. Oaksford (Eds.), Emotional cognition: From brain to behavior (pp. 9-34). London: Benjamins.

Burke, A., Heuer, F., \& Reisberg, D. (1992). Remembering emotional events. Memory \& Cognition, 20, 277-290.

Carstensen, L. L., \& TurK-CharLes, S. (1994). The salience of emotion across the adult life span. Psychology \& Aging, 9, 259-264.

Charles, S. T., Mather, M., \& Carstensen, L. L. (2003). Aging and emotional memory: The forgettable nature of negative images for older adults. Journal of Experimental Psychology: General, 132, 310-324.

CHRISTIANSON, S.-Å. (ED.) (1992). Handbook of memory and emotion: Research and theory. Hillsdale, NJ: Erlbaum.

Christianson, S.-Å., \& Loftus, E. F. (1987). Memory for traumatic events. Applied Cognitive Psychology, 1, 225-239.

Christianson, S.-A., \& LofTUS, E. F. (1991). Remembering emotional events: The fate of detailed information. Cognition \& Emotion, 5, 81-108.

Cohen, G., Conway, M. A., \& MaYlor, E. A. (1994). Flashbulb memories in older adults. Psychology \& Aging, 9, 454-463.

Cook, S., \& Wilding, J. (1997). Earwitness testimony: Never mind the variety, hear the length. Applied Cognitive Psychology, 11, 95-111.

D'Argembeau, A., \& VAN DER LindEN, M. (2004). Influence of affective meaning on memory for contextual information. Emotion, 4, 173-188.

David, B., Littrell, L., Kaszniak, A. W., \& Nielsen, L. (2002, February). Emotional experience and aging. Poster presented at the 13th Annual Meeting of the International Neuropsychological Society, Toronto.

Davidson, P. S. R., Cook, S. P., \& Glisky, E. L. (2006). Flashbulb memories for September 11th can be preserved in older adults. Aging, Neuropsychology, \& Cognition, 13, 196-206.

DAVIDSON, P. S. R., \& GLISKY, E. L. (2002). Is flashbulb memory a special instance of source memory? Evidence from older adults. Memory, 10, 99-111.

Denberg, N. L., Buchanan, T. W., Tranel, D., \& Adolphs, R. (2003). Evidence for preserved emotional memory in normal older persons. Emotion, 3, 239-253.

Dodson, C. S., Holland, P. W., \& Shimamura, A. P. (1998). On the recollection of specific- and partial-source information. Journal of Experimental Psychology: Learning, Memory, \& Cognition, 24, 11211136.

Doerksen, S., \& Shimamura, A. P. (2001). Source memory enhancement for emotional words. Emotion, 1, 5-11.

Dutton, A., \& CARroll, M. (2001). Eyewitness testimony: Effects of source of arousal on memory, source-monitoring, and metamemory judgments. Australian Journal of Psychology, 53, 83-91.

EASTERBrooK, J. A. (1959). The effect of emotion on cue utilization and the organization of behavior. Psychological Review, 66, 183-201.

Ferguson, S. A., Hashtroudi, S., \& Johnson, M. K. (1992). Age differences in using source-relevant cues. Psychology \& Aging, 7, 443452 .

Geghman, K. D., \& Multhaup, K. S. (2004). How generation affects source memory. Memory \& Cognition, 32, 819-823.

Glisky, E. L., Polster, M. R., \& Routhieaux, B. C. (1995). Double dissociation between item and source memory. Neuropsychology, $\mathbf{9}$, 229-235.

Glisky, E. L., Rubin, S. R., \& Davidson, P. S. R. (2001). Source memory in older adults: An encoding or retrieval problem? Journal of Experimental Psychology: Learning, Memory, \& Cognition, 27, 1131-1146.

HAMANN, S. [B.] (2001). Cognitive and neural mechanisms of emotional memory. Trends in Cognitive Sciences, 5, 394-400.

Hamann, S. B., Monarch, E. S., \& Goldstein, F. C. (2000). Memory enhancement for emotional stimuli is impaired in early Alzheimer's disease. Neuropsychology, 14, 82-92.

Hashtroudi, S., Johnson, M. K., VNEK, N., \& Ferguson, S. A. (1994). Aging and the effects of affective and factual focus on source monitoring and recall. Psychology \& Aging, 9, 160-170.

HEDDEN, T., \& GABRIELI, J. D. E. (2004). Insights into the ageing mind: A view from cognitive neuroscience. Nature Reviews Neuroscience, 5, 87-96. 
Henkel, L. A., Johnson, M. K., \& De Leonardis, D. M. (1998). Aging and source monitoring: Cognitive processes and neuropsychological correlates. Journal of Experimental Psychology: General, 127, 251268.

Herzog, A. G., \& Kemper, T. L. (1980). Amygdaloid changes in aging and dementia. Archives of Neurology, 37, 625-629.

HeUER, F., \& ReISBERG, D. (1990). Vivid memories of emotional events: The accuracy of remembered minutiae. Memory \& Cognition, 18, 496-506.

HeUER, F., \& Reisberg, D. (1992). Emotion, arousal, and memory for detail. In S.-Å. Christianson (Ed.), Handbook of memory and emotion: Research and theory (pp. 151-180). Hillsdale, NJ: Erlbaum.

Jack, C. R., Jr., Petersen, R. C., Xu, Y. C., Waring, S. C., O'Brien, P. C., TAngalos, E. G., ET AL. (1997). Medial temporal atrophy on MRI in normal aging and very mild Alzheimer's disease. Neurology, 49, 786-794.

JoHnSON, M. K., Nolde, S. F., \& De Leonardis, D. M. (1996). Emotional focus and source monitoring. Journal of Memory \& Language, 35, 135-156.

JuRICA, P. J., \& Shimamura, A. P. (1999). Monitoring item and source information: Evidence for a negative generation effect in source memory. Memory \& Cognition, 27, 648-656.

Kahneman, D. (1973). Attention and effort. Englewood Cliffs, NJ: Prentice Hall.

Kensinger, E. A., Brierley, B., Medford, N., Growdon, J. H., \& Corkin, S. (2002). Effects of normal aging and Alzheimer's disease on emotional memory. Emotion, 2, 118-134.

Kensinger, E. A., \& Corkin, S. (2003). Memory enhancement for emotional words: Are emotional words more vividly remembered than neutral words? Memory \& Cognition, 31, 1169-1180.

Kensinger, E. A., Piguet, O., Krendl, A. C., \& Corkin, S. (2005). Memory for contextual details: Effects of emotion and aging. Psychology \& Aging, 20, 241-250.

KučERA, H., \& FrancIS, W. N. (1967). Computational analysis of present-day American English. Providence, RI: Brown University Press.

LaBar, K. S., \& Phelps, E. A. (1998). Arousal-mediated memory consolidation: Role of the medial temporal lobe in humans. Psychological Science, 9, 490-493.

LEIGLAND, L. A., SCHUlz, L. E., \& JANOWSKy, J. S. (2004). Age related changes in emotional memory. Neurobiology of Aging, 25, 11171124.

Levenson, R. W., Carstensen, L. L., Friesen, W. V., \& Ekman, P. (1991). Emotion, physiology, and expression in old age. Psychology \& Aging, 6, 28-35.

LEVINE, L. J., \& BLUCK, S. (1997). Experienced and remembered emotional intensity in older adults. Psychology \& Aging, 12, 514-523.

LiBKuman, T. M., Nichols-WhitEHEAD, P., GRIFFITH, J., \& THOMAS, R. (1999). Source of arousal and memory for detail. Memory \& Cognition, 27, 166-190.

MACAUley, D., RYAN, L., \& Eich, E. (1993). Mood dependence in implicit and explicit memory. In P. Graf \& M. E. J. Masson (Eds.), Implicit memory: New directions in cognition, development, and neuropsychology (pp. 75-94). Hillsdale, NJ: Erlbaum.

MacKay, D. G., \& Ahmetzanov, M. V. (2005). Emotion, memory, and attention in the taboo Stroop paradigm: An experimental analogue of flashbulb memories. Psychological Science, 16, 25-32.

Malatesta, C. Z., \& KALNOK, M. (1984). Emotional experience in younger and older adults. Journal of Gerontology, 39, 301-308.

Maratos, E. J., \& RUGG, M. D. (2001). Electrophysiological correlates of the retrieval of emotional and non-emotional context. Journal of Cognitive Neuroscience, 13, 877-891.

MATHER, M., \& CARSTENSEN, L. L. (2005). Aging and motivated cognition: The positivity effect in attention and memory. Trends in Cognitive Sciences, 9, 496-502.

MCINTYRE, J. S., \& CRAIK, F. I. M. (1987). Age differences in memory for item and source information. Canadian Journal of Psychology, 41, 175-192.

Mitchell, K. J., Johnson, M. K., Raye, C. L., Mather, M., \& D'Esposito, M. (2000). Aging and reflective processes of working memory: Binding and test load deficits. Psychology \& Aging, 15, 527-541.
Multhaup, K. S. (1995). Aging, source, and decision criteria: When false fame errors do and do not occur. Psychology \& Aging, 10, 492497.

Naveh-Benjamin, M., \& Craik, F. I. M. (1996). Effects of perceptual and conceptual processing on memory for words and voice: Different patterns for young and old. Quarterly Journal of Experimental Psychology, 49A, 780-796.

Neisser, U., \& Libby, L. K. (2000). Remembering life experiences. In E. Tulving \& F. I. M. Craik (Eds.), The Oxford handbook of memory (pp. 315-332). New York: Oxford University Press.

Otani, H., Kusumi, T., Kato, K., Matsuda, K., Kern, R. P., Widner, R., JR., \& OHTA, N. (2005). Remembering a nuclear accident in Japan: Did it trigger flashbulb memories? Memory, 13, 6-20.

Pillemer, D. B. (1998). Momentous events, vivid memories. Cambridge, MA: Harvard University Press.

Prull, M. W., Gabrieli, J. D. E., \& Bunge, S. A. (2000). Age-related changes in memory: A cognitive neuroscience perspective. In F. I. M. Craik \& T. A. Salthouse (Eds.), Handbook of aging and cognition (2nd ed., pp. 91-153). Mahwah, NJ: Erlbaum.

Read, D., \& Craik, F. I. M. (1995). Earwitness identification: Some influences on voice recognition. Journal of Experimental Psychology: Applied, 1, 6-18.

ReISBERG, D., \& Heuer, F. (2003). Memory for emotional events. In D. Reisberg \& P. Hertel (Eds.), Memory and emotion (pp. 3-41). New York: Oxford University Press.

Revelle, W., \& Loftus, D. A. (1992). The implications of arousal effects for the study of affect and memory. In S.-Å. Christianson (Ed.), Handbook of memory and emotion: Research and theory (pp. 113149). Hillsdale, NJ: Erlbaum.

Schacter, D. L., Kaszniak, A. W., Kihlstrom, J. F., \& Valdiserri, M. (1991). The relation between source memory and aging. Psychology \& Aging, 6, 559-568.

SHIMAMURA, A. P. (2003, October). Attentional and emotional effects on source memory. Paper presented at a colloquium to the Department of Psychology, University of Arizona.

Smith, C. D., Malcein, M., Meurer, K., Schmitt, F. A., MarkesBery, W. R., \& Pettigrew, L. C. (1999). MRI temporal lobe volume measures and neuropsychologic function in Alzheimer's disease. Journal of Neuroimaging, 9, 2-9.

SPENCER, W. D., \& RAZ, N. (1994). Memory for facts, source, and context: Can frontal lobe dysfunction explain age-related differences? Psychology \& Aging, 9, 149-159.

SPENCER, W. D., \& RAZ, N. (1995). Differential effects of aging on memory for content and context: A meta-analysis. Psychology \& Aging, 10, 527-539.

TALMI, D., \& MosCoviTch, M. (2004). Can semantic relatedness explain the enhancement of memory for emotional words? Memory \& Cognition, 32, 742-751.

TeKCAN, A. I., \& PeYnircioğLu, Z. F. (2002). Effects of age on flashbulb memories. Psychology \& Aging, 17, 416-422.

Trott, C. T., Friedman, D., RitTer, W., \& Fabiani, M. (1997). Item and source memory: Differential age effects revealed by event-related potentials. NeuroReport, 8, 3373-3378.

Wessel, I., van der Kooy, P., \& Merckelbach, H. (2000). Differential recall of central and peripheral details of emotional slides is not a stable phenomenon. Memory, 8, 95-109.

Wright, D. B., Gaskell, G. D., \& O'Muircheartaigh, C. A. (1998). Flashbulb memory assumptions: Using national surveys to explore cognitive phenomena. British Journal of Psychology, 89, 103-121.

YodER, C. Y., \& Elias, J. W. (1987). Age, affect, and memory for pictorial story sequences. British Journal of Psychology, 78, 545-549.

\section{NOTES}

1. Twenty of the older adults received four presentations of the list. Later analyses indicated no differences in the pattern of results for those receiving three versus four presentations.

2. To examine the possibility that making the tone of voice emotional may have benefited item memory in speed, if not accuracy, reaction time (RT) from stimulus offset was also examined here. A 2 (age group: young or older $) \times 2$ (sentence type: emotional or neutral) $\times 2$ (tone of voice: emotional or neutral) mixed ANOVA for RT to item hits showed 
only that the young adults were faster to respond than the older adults $\left[F(1,91)=28.66, M S_{\mathrm{e}}=345,256.44, p<.001\right]$. In general, there was a high degree of variability in RT, but the pattern of the means did not support the hypothesis that a benefit would be conferred by presenting sentences in an emotional $(M=603 \mathrm{msec})$ versus a neutral $(M=$ $561 \mathrm{msec}$ ) tone.

3. The question of whether both age groups showed a similar item memory advantage for emotional content was complicated by the fact that the young and the older adults had different levels of accuracy over- all. To take account of this, we also calculated item memory scores, using the formula (emotional mean minus neutral mean) / [(emotional mean plus neutral mean)/2] to determine whether an effect of age would be significant. However, the younger and the older groups showed equivalent benefits of emotional content on item memory in Experiments 1, $3 \mathrm{~A}$, and $3 \mathrm{~B}$.

(Manuscript received October 15, 2004; revision accepted for publication April 23, 2006.) 